\title{
Research Paper: Effectiveness of Transactional Analysis Group Training in Reducing Control-oriented Behaviors of Spouse in Marital Conflicts
}

Emad Alkasir ${ }^{1}$, Fatemeh Jafarian Dehkordi ${ }^{\star *}$, Parvaneh Mohammadkhani ${ }^{1}$, Erfan Soleimani Sefat ${ }^{3}$, Akbar Atadokht $^{2}$

1. Department of Clinical Psychology, University of Social Welfare and Rehabilitation Sciences, Tehran, Iran.

2. Department of Psychology, Faculty of Education and Psychology, University of Mohaghegh Ardabili, Ardabil, Iran.

3. Department of Counseling, University of Social Welfare and Rehabilitation Sciences, Tehran, Iran.

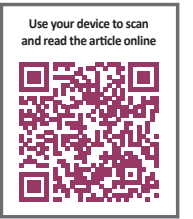

Citation: Alkasir E, Jafarian Dehkordi F, Mohammadkhani P, Soleimani Sefat E, Atadokht A. Effectiveness of Transactional Analysis Group Training in Reducing Control-oriented Behaviors of Spouse in Marital Conflicts. Iranian Rehabilitation Journal. 2017; 15(1):57-64. https://doi.org/10.18869/nrip.irj.15.1.57

https://doi.org/10.18869/nrip.irj.15.1.57

Article info:

Received: 10 Oct. 2016

Accepted: 23 Jan. 2017

\section{Keywords:}

Transactional analysis, Controloriented behavior, Family, Marital conflict

\section{ABSTRACT}

Objectives: The aim of this study was to examine the effectiveness of transactional analysis group training in reducing control-oriented behaviors of spouse in marital discords.

Methods: This study employed an experimental design with pre-test and post-test and a control group. The population consisted of women having marital disputes who were referred to counseling centers of Shahre-kord in the first six months of 2013. Among the sample, 40 individuals were randomly selected and assigned to two (experimental and control) groups of 20 members each. The subjects of the experimental group received eight transactional analysis training sessions, and control-oriented behavior scale of couple was used to collect data. The data obtained were analyzed by covariance analysis.

Results: The results showed that there is a significant difference between experimental and control groups in the post-test in terms of control-oriented behaviors of spouse and its dimensions $(\mathrm{P}<0.05)$

Discussion: According to our findings, the use of transactional analysis training is effective in reducing marital discords and can be extended to other aspects of life that can help couples and families prevent and reduce problems.

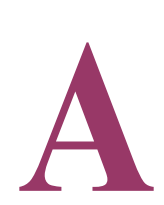

\section{Introduction}

Family is a basic unit of personal development and a place to create experiences that are essential for character building [1]. As the smallest social institu- tion, families are considered the most vulnerable social groups against damage. This is because the majority of injuries and problems occur first in the family and then penetrate into the community in the case of inappropriate management of the problems [2].

* Corresponding Author:

Fatemeh Jafarian Dehkordi, MSc.

Address: Department of Psychology, Faculty of Education and Psychology, University of Mohaghegh Ardabili, Ardabil, Iran.

Tel: +98 (916) 8047848

E-mail:fateme69jafarian@yahoo.com 
Divorce cases have become a serious social problem, causing damage to the community structure. The increasing divorce cases might be due to the widespread impact of population growth and significant changes in the family structure [3]. According to the civil registration of divorce, there has been a significant increase in divorce cases on an annual basis. There can be many adverse consequences of divorce on the extended family structure. Such consequences include changing of cultural, social, and economic laws, increased crime rates, social disintegration, development of extramarital relationships, physical and mental disorders such as addiction, suicidal tendencies, mental weaknesses, etc., less satisfaction with life, and increased rate of prostitution [4]. Divorced women are the most affected; they have a low quality of life [5], face financial issues [6], face negative moral attitude of the community, and have a tendency to drift towards drugs and depression [7].

One of the aspects of family conflicts or damages that can lead to divorce is the control-oriented behavior of the spouse. The most significant research topics have been regarding health education and violence in families, especially men's violence against women [8]. Wallace's definition of violence refers to the set of actions that are physically or emotionally harmful or potentially cause injury. Spouses use various forms of violence including physical, sexual, and emotional violence in their relationship at times. Control-oriented behaviors are the ones by which some couples try to harass their opponent. These behaviors can include economic control, control through threats and intimidation, isolation, and emotional control [9]. Some men show social violence (controlling female behavior, social isolation and a ban on communicating with others) against women. This social violence and control-oriented behavior is a barrier to healthy relationships in couples and have a negative impact on family functioning [8].

These are the root causes for misunderstandings, which result in biases and irrational thoughts [10]. The controloriented behaviors of spouses increase the conflicts between couples, and decreasing this behavior can play an important role in increasing marital satisfaction and thus, reducing the rate of divorce. One of the factors in the control-oriented behavior of spouse is the type of relationship shared by the couples, which is one of the ways to enhance communication-oriented couples in which spouse can have effective control behaviors that can be explained by transactional analysis training. Corey [11] argues that transactional analysis is an interactive treatment method that asserts on the cognitive and behavioral aspects of the healing process and aims to increase the awareness and ability of the individuals to decide and change their life. The effectiveness of communication skill training in reducing conflicts has been examined and confirmed in several studies $[12,13]$. One study [14] has reported the effectiveness of transactional analysis on the relationship between couples while another study [15] has stated the effectiveness of communication skills training in improving marital relations, reducing conflicts, and increasing their mental health. A research [16] based on transactional analysis training showed how the training increased intimacy between couples. Another study [17] based on transactional analysis showed its effectiveness in increasing consistency and improving the relationship between couples.

Despite different studies confirming the effectiveness of transactional analysis in improving communication among couples, the effectiveness of this intervention in reducing control-oriented behaviors of spouse has not been significantly addressed. Therefore, this study attempts to show the effectiveness of transactional analysis training in reducing the control-oriented behaviors of spouse.

\section{Methods}

This study employed an experimental design with pre-test and post-test and a control group. The training transactional analysis was considered as an independent variable, whereas the control-oriented behavior was considered as a dependent variable.

\section{Population, sample and sampling method}

The population of this study included all women with marital conflicts who were aged 20 to 50 years old and were literate in Shahrekord City in the first six months of 2013. Due to family problems, they were referred to counseling centers and welfare organization across the city (name). After coordination and referral to counseling centers and welfare organizations, 40 patients were randomly selected and assigned to two groups of 20 people each (Department of transactional analysis and control group). The following instruments were used to collect data:

\section{Controlling behaviors scales:}

This scale was used in 2005 by Graham-Kevan and Archer to evaluate the control-oriented behavior of individuals. It is a phrase that control-oriented behavior scale 24 of the couples' married life is examined. For couples with children, five other words were added to the scale (five was the final test). This scale only deals with behavioral categories and does not cover physical 
Table 1: Implementation instructions of transactional analysis training

\begin{tabular}{|c|c|}
\hline First session & $\begin{array}{l}\text { Referrals, stating study objectives, the rules of the group, responsibility for members of the group, general com- } \\
\text { ment about transactional analysis and its application, pre-test }\end{array}$ \\
\hline Second session & $\begin{array}{l}\text { Action analysis of child, adult and parent mode, assignment to participants about charting their soul states or ego } \\
\text { grams, expression, natural child and obedient child, controlling parent and supportive parent features, strengthen } \\
\text { adult }\end{array}$ \\
\hline Third session & $\begin{array}{l}\text { The definition of mutual relationship, parallel reciprocal relationship, intersecting mutual relationship, the rules of } \\
\text { established relationship, assignment of subjects to detect any types of reciprocity relationships }\end{array}$ \\
\hline Fourth session & $\begin{array}{l}\text { The definition of stroking, verbal / non-verbal, positive / negative, conditional / unconditional stroking, discussing } \\
\text { ways to be fondled and submit assignments related to participants }\end{array}$ \\
\hline Fifth session & $\begin{array}{c}\text { Detect covert exchanging, tangential relations / blocking relations, discussion and detection of covert exchanging } \\
\text { by participants }\end{array}$ \\
\hline Sixth session & How to have a more active adult, organizing time, assignment of participants \\
\hline Seventh session & $\begin{array}{l}\text { Further explanation of the mental games, describing the state of life, neutralizing the parent and assignment to } \\
\text { participants in the case of detection methods to neutralize the opponent's parent }\end{array}$ \\
\hline Eighth session & $\begin{array}{l}\text { Summarize and review the content with an emphasis on its use by an adult to improve relations and living condi- } \\
\text { tions, the decision to continue this life, prepare to say goodbye to the group, the post-test implementation }\end{array}$ \\
\hline
\end{tabular}

Iranian Rehabilitation \ournal

aggression. The questionnaire was designed so that the person can report his/her controlling behavior and the spouse's controlling behavior. The participants were identified on a 5-point Likert scale (from 0 to 4 ) that explained the extent of his/her behavior. The scale includes five sub-scales (with respect to the expressions relating to children, six subscales), i.e. economic control (Expressions 1 to 4), intimidating control (Expressions 5 to 8), control through intimidation (expressions 9 to 13), emotional control (Expressions 14 to 18), and control by isolation (Expressions 19 to 24). The results showed that the controlling behaviors scale has a good overall internal consistency [18]. The Cronbach's alpha value was calculated $(\alpha=0.75)$, which indicated the reliability of the research instrument.

Experts confirmed the validity of the questionnaire. For the experimental group, transactional analysis training was conducted in 8 sessions [19] as shown in Table 1. Data analysis method: Statistical methods were employed in this study. In the field of descriptive statistics, the mean, standard deviation, and covariance analysis were used to test the hypotheses. Data were analyzed using SPSS software (Version, Country).

\section{Results}

The demographic information of the study population is shown in Table 2. The mean marriage age of participants was 31.28 years, and the mean length of marriage was 6.27 years. There was no perceptible difference between the control and experimental groups in terms of mean age of marriage. Table 3 shows that the majority of subjects $(\mathrm{n}=37)$ had a diploma or high school diploma and only three of them had a degree below diploma.

Table 4 shows that the mean scores of control-oriented behavior of the wife in the experimental group reduced from 43.85 to 21.80 while in the control group, no significant difference was observed between the mean scores of the control-oriented behavior in pre-test and post-test. In control-oriented behavior, the same changes could be seen with high and low intensity.

Table 5 shows that the mean scores of control-oriented behavior of the husband in the experimental group reduced from 46.70 to 28.75 while in the control group, no significant difference was observed between the mean scores of the control-oriented behavior in pre-test and post-test. In control-oriented behavior, the same changes were seen with high and low intensity.

Table 6 shows that there is a significant statistical difference between the mean scores of control and experimental groups in the dimensions of spouse's economic control, control through intimidation, emotional control, control by isolation and via children $(\mathrm{P}<0.001)$, along with the total scores of the women's control behavior. Significant levels were obtained from the analysis of homogeneity of variance error $(\mathrm{P}<0.05)$, indicating default homogeneity of variance between the groups in all components of error and no problem to use parametric tests.

Table 7 shows that there is a significant statistical difference between the mean scores of control and experimental groups in dimensions of spouse's economic control, control through intimidation, controlling through 
Table 2. Age and duration of marriage of experimental and control groups

\begin{tabular}{cccc}
\hline Group & Variable & Age & Marriage Duration \\
\hline \multirow{2}{*}{ Experiment } & Mean & 31.80 & 6.90 \\
& Standard deviation & 8.370 & 5.767 \\
Control & Mean & 30.75 & 5.65 \\
& Standard deviation & 7.704 & 4.416 \\
Total & Mean & 31.28 & 6.27 \\
& Standard deviation & 7.958 & 5.109 \\
\hline
\end{tabular}

Iranian Rehabilitation Journal

Table 3. Distribution of participants based on the grade divided by category

\begin{tabular}{cccc}
\hline Group & Under Diploma & Diploma & BA and Higher \\
\hline Control & 2 & 8 & 10 \\
Experiment & 1 & 8 & 11 \\
Total & 3 & 16 & 21 \\
\hline
\end{tabular}

Iranian Rehabilitation Journal

intimidation, emotional control, control by isolating and controlling via children $(\mathrm{P}<0.001)$ As well as the total scores of the women's control behavior. Significant levels obtained from the analysis of homogeneity of variance error $(\mathrm{P}<0.05)$ indicate that the default homogeneity of variance between groups in all components of error and no problem to use parametric tests.

\section{Discussion}

The results showed that transactional analysis training reduced control-oriented behavior and its dimensions of spouse in the experimental group compared to the control group.

This result is consistent with the results of a previous research [20], which showed that couples who partici-

Table 4. Mean and standard deviation of pre-test and post-test of the component of control-oriented behaviors of wife to separate the control and the experiment group

\begin{tabular}{ccccccccc}
\hline & \multicolumn{4}{c}{ Experiment } & \multicolumn{3}{c}{ Control } \\
\cline { 2 - 9 } Variables & \multicolumn{2}{c}{ Pre-Test } & \multicolumn{2}{c}{ Post-Test } & \multicolumn{2}{c}{ Pre-Test } & Post-Test \\
\cline { 2 - 10 } & M & SD & M & SD & M & SD & M & SD \\
\hline Economic control & 7.55 & 3.12 & 4.05 & 1.79 & 10.20 & 2.66 & 10.15 & 2.60 \\
\hline Control through threats & 7.50 & 3.84 & 2.70 & 1.45 & 10.85 & 2.05 & 10.95 & 1.90 \\
\hline Control through intimidation & 8.00 & 3.93 & 3.20 & 1.54 & 11.05 & 2.68 & 11.00 & 3.044 \\
\hline Emotion control & 8.45 & 3.51 & 5.00 & 2.20 & 13.40 & 1.75 & 13.60 & 1.984 \\
\hline Control through isolating & 12.35 & 4.66 & 6.85 & 2.75 & 15.25 & 2.59 & 41.80 & 2.33 \\
\hline Control through children & 6.89 & 3.68 & 2.78 & 1.56 & 9.71 & 2.57 & 9.71 & 2.69 \\
\hline Controlling behaviors & 43.85 & 12.35 & 21.80 & 4.62 & 60.75 & 5.46 & 57.45 & 3.70 \\
\hline
\end{tabular}

Mranian Rehabilitation Journa 
Table 5. Mean and standard deviation of pre-test and post-test of the component of control-oriented behaviors of husband to separate the control and the experiment group

\begin{tabular}{|cccccccccc}
\hline & \multicolumn{4}{c}{ Experiment } & \multicolumn{3}{c}{ Control } \\
\cline { 2 - 9 } Variables & \multicolumn{2}{c}{ Pre-Test } & \multicolumn{2}{c}{ Post-Test } & \multicolumn{2}{c}{ Pre-Test } & \multicolumn{2}{c}{ Post-Test } \\
\cline { 2 - 9 } & M & SD & M & SD & M & SD & M & SD \\
\hline Economic control & 8.65 & 3.91 & 6.30 & 2.97 & 10.50 & 2.35 & 10.25 & 2.099 \\
\hline Control through threats & 7.40 & 4.70 & 3.85 & 2.36 & 9.45 & 1.87 & 9.50 & 2.14 \\
\hline Control through intimidation & 9.10 & 3.82 & 4.85 & 2.46 & 11.50 & 2.14 & 11.25 & 1.71 \\
\hline Emotion control & 9.55 & 4.65 & 6.20 & 3.15 & 11.40 & 1.90 & 12.30 & 1.62 \\
\hline Control through isolating & 12.00 & 4.37 & 7.55 & 2.91 & 13.65 & 1.72 & 14.15 & 2.03 \\
\hline Control through children & 8.22 & 4.23 & 3.78 & 1.78 & 12.43 & 1.81 & 11.57 & 2.57 \\
\hline Controlling behaviors & 46.70 & 16.700 & 28.75 & 9.95 & 60.75 & 5.466 & 57.45 & 3.70 \\
\hline
\end{tabular}

Iranian Rehabilitation Journal

Table 6. Covariance analysis of post-test scores of components of control-oriented behavior of female participants of the control and experiment group with controlling the effect of pre-test

\begin{tabular}{cccccccc}
\hline Variables & \multicolumn{2}{c}{$\begin{array}{c}\text { The Homeneity of Error } \\
\text { Variance }\end{array}$} & \multicolumn{2}{c}{ Pre-Test Effect } & & Group \\
& $\mathbf{F}$ & $\mathbf{P}$ & $\mathbf{F}$ & $\mathbf{P}$ & $\mathbf{F}$ & $\mathbf{P}$ & Etha-Square \\
\hline Economic control & 1.05 & 0.31 & 61.88 & $<0.001$ & 86.16 & $<0.001$ & 0.700 \\
\hline Control through threats & 2.16 & 0.15 & 24.80 & $<0.001$ & 216.84 & $<0.001$ & 0.85 \\
\hline Control through intimidation & 0.76 & 0.38 & 15.82 & $<0.001$ & 85.66 & $<0.001$ & 0.61 \\
\hline Emotion control & 0.005 & 0.94 & 38.10 & $<0.001$ & 87.42 & $<0.001$ & 0.70 \\
\hline Control through isolating & 0.74 & 0.39 & 45.01 & $<0.001$ & 120.84 & $<0.001$ & 0.76 \\
\hline Control through children & 0.28 & 0.60 & 11.93 & $<0.001$ & 41.89 & $<0.001$ & 0.76 \\
\hline Controlling behaviors & 1.18 & 0.28 & 28.26 & $<0.001$ & 388.61 & $<0.001$ & 0.91 \\
\hline
\end{tabular}

Iranian Rehabilitation Journal

Table 7. Covariance analysis of post-test scores of components of control-oriented behavior of male participants of the control and experiment group with controlling the effect of pre-test

\begin{tabular}{ccccccccc}
\hline Variables & \multicolumn{2}{c}{$\begin{array}{c}\text { The Homogeneity of Er- } \\
\text { ror Variance }\end{array}$} & \multicolumn{2}{c}{ Pre-Test Effect } & & \multicolumn{2}{c}{ Group } \\
& $\mathbf{F}$ & $\mathbf{P}$ & $\mathbf{F}$ & $\mathbf{P}$ & $\mathbf{F}$ & $\mathbf{P}$ & Etha-Square \\
\hline Economic control & 4.22 & 0.047 & 21.179 & $<0.001$ & 41.91 & $<0.001$ & 0.53 \\
Control through threats & 0.32 & 0.572 & 48.78 & $<0.001$ & 89.22 & $<0.001$ & 0.70 \\
\hline Control through intimidation & 2.55 & 0.118 & 22.33 & $<0.001$ & 77.66 & $<0.001$ & 0.67 \\
$\quad$ Emotion control & 2.86 & 0.099 & 63.51 & $<0.001$ & 100.39 & $<0.001$ & 0.73 \\
Control through isolating & 4.06 & 0.050 & 34.86 & $<0.001$ & 92.61 & $<0.001$ & 0.71 \\
Control through children & 5.79 & 0.030 & 9.33 & $<0.001$ & 34.84 & $<0.001$ & 0.73 \\
\hline Controlling behaviors & 11.33 & 0.002 & 74.61 & $<0.001$ & 251.85 & $<0.001$ & 0.87 \\
\hline
\end{tabular}

Iranian Rehabilitation Journal 
pated in the courses on communication skills had more effective relations and coped up in a better manner experiencing less conflict. Research [21] also showed that transactional analysis training caused revision of prejudices and controlled impulsivity of parents.

Our findings are also consistent with research [22] that showed transactional analysis training led to increased marital adjustment, positive emotions couple, marital satisfaction, marital intimacy, and reduction of volatility. In addition, this is consistent with the study [17] that showed transactional analysis training enhanced compatibility in dimensions of family, emotional, occupational, social, and improvement of communication between couples, parents and children. Another study [23] showed that transactional analysis training improved lovemaking styles. Studies [24] have also showed that this training increased empathy, creativity, and tolerance level of the couples. In fact, the training makes people equipped with good communication skills along with the diagnosis of scenarios of self and others with regard to verbal and nonverbal clues to establish an appropriate complementary relationship. In addition, using the techniques of driving the other, the parent can cause situations of potential conflict, well with adult supervision by strengthening its position, department, the conditions for constructive ties, and not the destruction and provide controllers. In fact, if people operate their adult I when controlling behavior is out of their hands since the adult I more deal with analysis, Training of Transactional Analysis grew adult I and the individual assesses the different circumstances and then treats which will have more control over his behavior.

It can be concluded that transactional analysis training reduced control-oriented behavior of spouse that caused conflicts and disputes among the couples. It also made the couples learn about the basics and further generalize it to other life issues and use them at different times while dealing with different people. This study was conducted with some limitations. Some of the training sessions were run by the researchers; hence, there may be certain biases when verifying the hypotheses. This study was limited to a single city, so further studies should generalize the findings to other cities and other women.

Based on the findings of this study, the following suggestions have been offered: 1) To validate the results, in future research, teaching methods should be offered by different specialists; 2) Support meetings after the training should be conducted from time to time to maintain the long-term effects of teaching and thinking; 3) Due to lack of enough time and money for continuing the study, follow-up is recommended to check the robustness of the results; 4) Transactional analysis should be provided in the form of pre-marriage education classes in order to prevent problems and increase the readiness of people to be trained in dealing with marital conflicts; 5) Due to lack of universal access to advisors, people specialized in family therapy and counseling should inform people about the importance of transactional analysis and its role in reducing behavior-oriented group. Medias be used.

\section{Acknowledgements}

This paper is extracted from the secopnd auther's $\mathrm{PhD}$ thesis, Department of Psychology, Faculty of Education and Psychology, University of Mohaghegh Ardabili. Authors are thankful to all the participants and colleagues who cooperated in the current study.

\section{Conflict of Interests}

The authors declared no conflict of interests.

\section{References}

[1] Carvalho JC, Freitas PP, Leuschner A, Olson DH. Healthy functioning in families with a schizophrenic parent. Journal of Family Psychotherapy. 2014; 25(1):1-11 .doi 10.1080/08975353.2014.881685

[2] Rafatjah M, Bahrami S. [The anthropological study of family disorganization factors in Sirus Region, Tehran (Persian)] Iranian Journal of Anthropology Research. 2011; 1(2):85-109.

[3] Sadrolashrafi M, Khonakdar-Taresi M, Shamkhani A, Yusefi-Afrashteh M. [Pathology of divorce (factors and causes) and solutions to prevent (Persian)]. Cultural Engineering. 2013; 7(73-74):26-53.

[4] Thompson RG, Lizardi D, Keyes KM, Hasin DS. Childhood or adolescent parental divorce/separation, parental history of alcohol problems, and offspring lifetime alcohol dependence. Drug and Alcohol Dependence. 2008; 98(3):264-9.doi: 10.1016/j.drugalcdep.2008.06.011

[5] Fukuda Y, Nakamura K, Takano T. Municipal health expectancy in Japan: Decreased healthy longevity of older people in socioeconomically disadvantaged areas. BMC Public Health. 2005; 5:65. doi: 10.1186/1471-2458-5-65

[6] Bowman S. Low economic status is associated with suboptimal intakes of nutritious foods by adults in the National Health and Nutrition Examination Survey 1999-2002. Nutrition Research. 2007; 27(9):515-23. doi: 10.1016/j.nutres.2007.06.010

[7] Amato PR, Previti D. People's reasons for divorcing gender social class, the life course, and adjustment. Journal of family issues. 2003; 24(5):602-26. doi: 10.1177/0192513×03254507 
[8] Narimani M, Agha-Mohamadian HR. [A Study of the extent of men's violence against women and its related variables among families inhabited in Ardabil City (Persian)]. Journal of Fundamentals of Mental Health. 2006; 7(27-28):107-13.

[9] Graham-Kevan N, Archer J. Intimate terrorism and common couple violence: A test of Johnson's predictions in four British samples. Journal of interpersonal violence. 2003; 18(11):124770. doi: $10.1177 / 0886260503256656$

[10] John G, Cliff N, Howard M, Steve B, Bruce Y, Mary Ellen R. Behavior exchange theory and marital decision making. Journal of Personality and Social Psychology. 1976; 34(1):14-23. doi: 10.1037/0022-3514.34.1.14

[11] Corey G. Theory and practice of counseling and psychotherapy. Ontario: Nelson Education; 2015.

[12] Amini M, Amini Y, Hosseinian S. [Efficacy of couples communication skills group training using interaction analysis approach (TA) on reducing marital conflicts (Persian)]. Journal of Family Counseling and Psychotherapy. 2013; 3(3):377401.

[13] Oanning H. The long-term effects of the couple communication program. Journal of Marital and Family Therapy. 1982; 8(4):463-8. doi: 10.1111/j.1752-0606.1982.tb01472.x

[14] Florio GA, Donnelly JP, Zevon MA. The structure of work-related stress and coping among oncology nurses in high-stress medical settings: A transactional analysis. Journal of Occupational Health Psychology. 1998; 3(3):227-42. doi: 10.1037/1076-8998.3.3.227

[15] Lundblad AM, Hansson K. Couples therapy: Effectiveness of treatment and long-term follow-up. Journal of Family Therapy. 2006; 28(2):136-52. doi: 10.1111/j.1467-6427.2006.00343.x

[16] Nayeri A, Lotfi M, Noorani M. The effectiveness of group training of transactional analysis on intimacy in couples. Procedia-Social and Behavioral Sciences. 2014; 152:1167-70. doi: 10.1016/j.sbspro.2014.09.294

[17] NejadnaderiS, Darehkordia M, Divsalar K. The study of adjustment changes after teaching of transactional analysis(TA) to the people. Journal of Humanities And Social Science. 1998; 10(5):31-4.

[18] Fischer J, Corcoran K. Measures for clinical practice: A source book. Volume 1: Couples, families, and children. New York: Oxford University Press; 2007.

[19] Kafi S, Molazdeh R, Nori M, Salahi I. [The effectiveness of transactional behavior analytic group therapy on the marital adjustment and prevention of relapse in detoxified people (Persian)]. Journal of Psychology (Tabriz University). 2011; 6(23):111-32.

[20] Sanderson CA, Karetsky KH. Intimacy goals and strategies of conflict resolution in dating relationships: A mediational analysis. Journal of Social and Personal Relationships. 2002; 19(3):317-37. doi: 10.1177/0265407502193002

[21] Kazemi Z, Neshatdust H, Kajbaf MB, Abedi A, Aghamohamadi S, Sadeghi S. [The effect of transactional analysis training on runaway girls' social intimacy in Isfahan a singlesubject design research (Persian)]. Women's Studies Sociological \& Psychological. 2011; 10(3):139-162.

[22] Akbari E, Poursharifi H, Azimi Z, Fahimi S, Amiri Pichakolaei A. [The effectiveness of transactional analysis group therapy on satisfaction, adjustment, positive feelings, and intimacy in couples with emotional divorce experience (Persian)]. Journal of Family Counseling \& Psychotherapy. 2013; 2(4):455-85.

[23] Sadeghi M, Ahmadi SA, Bahrami F, Etemadi O, Pourseyed $\mathrm{S}$. [The effect of transactional analysis training on love styles of couples (Persian)]. Journal of Researches of Cognitive and Behavioral Sciences. 2104; 3(2):71-84.

[24] Ciucur D. A transactional analysis group psychotherapy programme for improving the qualities and abilities of future psychologists. Procedia-Social and Behavioral Sciences. 2013; 78:576-80. doi: 10.1016/j.sbspro.2013.04.354 
